\title{
Pengaruh Kompetensi Strategi Dan Kompetensi Etika Terhadap Pertumbuhan Usaha Yang Dimediasi Oleh Kompetensi Jaringan
}

\author{
Venia dan Frangky Slamet \\ Program Studi Manajemen, Fakultas Ekonomi dan Bisnis \\ Universitas Tarumanagara, Jakarta \\ Email: venia.115160104@stu.untar.ac.id dan frangkys@fe.untar.ac.id
}

\begin{abstract}
The purpose of this research to examine whether 1) The influence between strategic competency on the business growth. 2) The influence between ethical competency on the business growth. 3) The influence between strategic competency on the network competence. 4) The influence between ethical competency on the network competence. 5) The influence of network competence as a mediation among strategic competency to business growth. 6) The influence of network competence as a mediation among ethical competency to business growth. 7) The influence between network competency on the business growth. Sample was selected using purposive sampling method amounted to 50 respondents at Tanah Abang, Central Jakarta. The result of this study show that strategic competency has positive and significant effect to business growth, ethical competency has negative and not significant effect to business growth, strategic competency has positive and significant effect to network competence, ethical competency has positive and significant effect to network competence, there are positive and significant influence between strategic competency on business growth with network competence as a mediating variable, there are positive and significant influence between ethical competency on business growth with network competence as a mediating variable, and network competence has positive and significant effect to business growth.
\end{abstract}

Keywords: Strategic Competency, Ethical Competency, Network Competence, and Business Growth.

Abstrak: Tujuan dari penelitian ini untuk menguji apakah 1) Pengaruh antara kompetensi strategis terhadap pertumbuhan bisnis. 2) Pengaruh antara kompetensi etika terhadap pertumbuhan bisnis. 3) Pengaruh antara kompetensi strategis pada kompetensi jaringan. 4) Pengaruh antara kompetensi etika pada kompetensi jaringan. 5) Pengaruh kompetensi jaringan sebagai mediasi antara kompetensi strategis terhadap pertumbuhan bisnis. 6) Pengaruh kompetensi jaringan sebagai mediasi antara kompetensi etis terhadap pertumbuhan bisnis. 7) Pengaruh antara kompetensi jaringan pada pertumbuhan bisnis. Sampel dipilih menggunakan metode purposive sampling berjumlah 50 responden di Tanah Abang, Jakarta Pusat. Hasil penelitian ini menunjukkan bahwa kompetensi strategis berpengaruh positif dan signifikan terhadap pertumbuhan bisnis, kompetensi etika berpengaruh negatif dan tidak signifikan terhadap pertumbuhan bisnis, kompetensi strategis berpengaruh positif dan signifikan terhadap kompetensi jaringan, kompetensi etika berpengaruh positif dan signifikan terhadap jaringan kompetensi, terdapat pengaruh positif dan signifikan antara kompetensi strategis terhadap pertumbuhan bisnis dengan kompetensi jaringan sebagai variabel mediasi, terdapat pengaruh positif dan signifikan antara kompetensi etika terhadap pertumbuhan bisnis dengan kompetensi jaringan sebagai 
variabel mediasi, dan kompetensi jaringan berpengaruh positif dan signifikan. untuk pertumbuhan bisnis.

Kata Kunci: kompetensi strategi, kompetensi etika, kompetensi jaringan, dan pertumbuhan usaha.

\section{LATAR BELAKANG}

UKM (Usaha Kecil dan Menengah) merupakan usaha dari masyarakat yang didirikan berdasarkan inisiatif individu itu sendiri. Berdasarkan data yang berasal dari Warta Ekonomi, jumlah UKM di Indonesia pada tahun 2019 hampir mencapai 63 juta usaha (www.wartaekonomi.co.id, Agustus 2019). Menurut OECD (Organization of Economic Cooperation Development) usaha UKM telah menyerap 76,3 persen tenaga kerja di Indonesia.

Menurut World Bank, sumber penghidupan di Indonesia sangat bergantung pada sektor UKM (www.goukm.id, September 2016). Dengan adanya UKM memunculkan persaingan, memberikan peluang kerja, dan juga memberikan peluang baru untuk bisnis yang selanjutnya dapat menekan tingkat pengangguran.

Dalam melakukan sebuah bisnis pertumbuhan usaha merupakan sebuah prioritas (Rosli \& Abdullah, 2015), karena memberikan peluang suatu usaha akan terus bertahan dan juga mengurangi kemungkinan usaha tersebut akan tutup (Rauch \& Rijskik, 2013).

Pertumbuhan usaha dapat dilihat dari adanya peningkatan dari jumlah permintaan akan produk maupun layanan yang secara langsung mempengaruhi peningkatan penjualan dan investasi terhadap faktor-faktor yang berkaitan dengan pertambahan produksi sehingga perusahaan dapat memenuhi peningkatan penjualan yang terjadi (Janssen, 2009).

Dalam pertumbuhan usaha, kompetensi kewirausahaan memberikan peran yang besar, di mana kompetensi kewirausahaan merupakan sifat yang mendasari pengusaha maupun individu dalam menyelesaikan tugas mereka dengan cara yang paling menguntungkan (Lazar \& Paul, 2015).

Kompetensi kewirausahaan yang kurang dapat menghambat keberhasilan dari UKM (Ahmad, 2007). Jika ingin mencapai keberhasilan, UKM harus mengembangkan usaha mereka melalui kompetensi yang mereka miliki.

Adapun dimensi dari kompetensi kewirausahaan terdiri atas kompetensi konseptual, kompetensi peluang, kompetensi pribadi, kompetensi belajar, kompetensi jaringan, kompetensi strategi, dan kompetensi etika (Man \& Lau, 2000).

Namun, menurut penelitian yang dilakukan oleh Colombo \& Grilli (2005) tidak semua kompetensi mempengaruhi pertumbuhan perusahaan. Hal ini diperjelas dengan adanya penelitian yang dilakukan oleh Aquilani et al., (2017) bahwa kompetensi strategi membuat seorang pengusaha lebih mengaplikasikan strateginya ke lingkungan eksternal bisnis demi mencapai pertumbuhan perusahaan. Sementara penelitian yang dilakukan oleh Spence \& Rutherfoord (2001) menyatakan bahwa kompetensi etika merupakan kunci untuk mencapai pertumbuhan perusahaan.

Tidak hanya kompetensi strategi dan kompetensi etika yang dapat mempengaruhi pertumbuhan usaha, ada juga kompetensi jaringan memiliki hubungan yang erat antara kompetensi strategi dan kompetensi etika, maka dari itu kompetensi jaringan dijadikan sebagai varaiabel mediasi. 
Keterkaitan ini dapat terlihat jelas antara kompetensi strategi dan kompetensi jaringan, di mana dalam mempersiapkan strategi usaha, sebuah usaha tentunya sangat memerlukan sumber daya informasi untuk melakukan strategi usaha demi mencapai keberhasilan usaha yang dapat diperoleh melalui adanya hubungan dengan pihak eksternal bisnis untuk mendapatkan informasi yang dibutuhkan oleh pelaku usaha. Seorang wirausaha akan mendapatkan informasi pasar tepat pada waktunya, jika ia memiliki hubungan dengan pihak eksternal bisnis seperti, pelanggan, pemasok, dan pihak yang terkait lainnya. Hal ini selaras dengan apa yang diungkapkan oleh Tehseen et al., (2019) adanya pengaruh positif antara kompetensi strategi dan kompetensi jaringan.

Selain itu menurut Tehseen et al., (2019) ketika sebuah pengusaha memiliki hubungan yang dekat dengan pelanggan, pemasok, dan pihak lainnya yang terkait, maka mereka dapat menjadi lebih transparan dalam menjalankan transaksi bisnis demi mempertahankan kepercayaan orang lain.

Dengan demikian, berdasarkan uraian sebelumnya, terdapat hubungan yang erat antara kompetensi jaringan dengan kompetensi strategi dan kompetensi etika. Penelitian Tehseen et al., (2019) terhadap usaha UKM grosir dan eceran di Malaysia memperlihatkan bahwa kompetensi strategi dan kompetensi etika memiliki pengaruh dalam mendorong pertumbuhan UKM pada saat kompetensi jaringan dijadikan sebagai variabel mediasi.

Berdasarkan hal tersebut, penelitian ini merupakan replikasi dari penelitian Tehseen yang dilakukan di Jakarta guna melihat apakah terdapat hubungan antara kompetensi strategi dan kompetensi etika terhadap pertumbuhan UKM dengan variabel mediasi, yaitu kompetensi jaringan. Berdasarkan data yang diperoleh di BPS (Badan Pusat Statistik) pada tahun 2006, jenis usaha UKM paling banyak bergerak di bidang grosir dan eceran, yaitu sebanyak 10.226.595 usaha, di mana Tanah Abang merupakan salah satu pusat perbelanjaan grosir dan eceran terbesar di Asia Tenggara, di mana di sana terdapat banyak UKM yang bergerak dibidang fashion khususnnya pakaian. Adapaun tujuan dari penelitian ini adalah untuk menguji secara empiris pengaruh antara kompetensi strategi dan pertumbuhan UKM, untuk menguji secara empiris pengaruh antara kompetensi etika dan pertumbuhan UKM, untuk menguji secara empiris apakah kompetensi strategi mempengaruhi kompetensi jaringan, untuk menguji secara empiris apakah kompetensi etika mempengaruhi kompetensi jaringan, untuk menguji secara empiris apakah kompetensi jaringan dapat memediasi pengaruh kompetensi strategi dan pertumbuhan UKM, untuk menguji secara empiris apakah kompetensi jaringan dapat memediasi pengaruh kompetensi etika dan pertumbuhan UKM, dan untuk menguji secara empiris pengaruh antara kompetensi jaringan dan pertumbuhan UKM.

\section{KAJIAN TEORI}

Resource Dependence Theory (RDT). Menurut RDT kelangsungan hidup dari usaha dimungkinkan dari kemampuan pengusaha dalam memperoleh dan mempertahankan sumber daya penting bagi usahanya, yaitu pihak eksternal termasuk di dalamnya seperti, pemasok, pelanggan, dan pihak yang terkait lainnya (Pfeffer \& Salancik, 1978).

Resource Based View (RBV). Menurut RBV sumber daya dan keahlian perusahaan penting bagi perusahaan, karena merupakan hal yang mendasar dari kemampuan dalam hal bersaing dan mencapai kinerja perusahaan. Dalam RBV, Barney (1991) mengatakan bahwa sumber daya manusia merupakan sumber daya yang berharga. 
Competencies Theory. Competencies Theory menurut Bird (1995) adalah kompetensi kewirausahaan yang merupakan sebuah mekanisme yang memungkinkan suatu bisnis dapat meningkatkan kesuksesan bisnis. Adapun dimensi dari kompetensi kewirausahaan adalah sebagai berikut:

1. Kompetensi strategi adalah kompetensi yang berkaitan dengan pangaturan, mengevaluasi dan juga mengimplementasi strategi suatu perusahaan.

2. Kompetensi konseptual adalah kemampuan konseptual yang tercermin pada perilaku pengusaha, seperti dalam hal mengeksplorasi iede-ide baru, berani dalam mengambil risiko, dan melihat masalah yang ada sebagai peluang.

3. Kompetensi peluang adalah kompetensi yang berkaitan dengan pengenalan terhadap peluang pasar, terkait dengan memahami kebutuhan pelanggan yang masih belum terpenuhi, secara aktif mencari produk maupun layanan yang memberikan manfaat kepada pelanggan dan mengidentifikasi barang maupun jasa yang diinginkan pelanggan.

4. Kompetensi jaringan adalah kompetensi dalam melakukan negosiasi dengan orang lain, menjaga kontrak kerja, berinteraksi secara efektif dengan orang lain, mengembangkan hubungan jangka panjang dengan orang lain dan saling percaya satu dengan yang lainnya.

5. Kompetensi belajar adalah kompetensi yang terkait dengan kemampuan belajar seseorang dari berbagai macam cara, belajar untuk bersikap proaktif, selalu mengikuti perkembangan dibidang terkait, dan menerapkan keterampilan serta pengetahuan yang telah dipelajari ke dalam praktik kerja nyata.

6. Kompetensi pribadi adalah kompetensi pribadi yang ditunjukkan melalui motivasi diri untuk mencapai kinerja yang optimal, menaggapi kritik, mempertahankan sikap proaktif, memprioritaskan tugas yang harus dikerjakan, memahami kekuatan dan kelamahan yang ada pada diri sendiri dan menyesuaikan dengan peluang dan ancaman yang ada.

7. Kompetensi etika adalah kompetensi dari individu untuk bersikap transparan dan jujur dalam melakukan transaksi bisnis dengan mengatakan yang sebenarnya terjadi dan mau mengakui kesalahan.

Kaitan Kompetensi Strategi dan Pertumbuhan Usaha. Menurut penelitian yang dilakukan Tamyez, Ali, dan Ishak (2017), dalam upaya tumbuh dan berhasil, sebuah usaha harus memiliki keunggulan kompetitif yang merupakan kunci utama sebuah usaha. Keunggulan kompetitif dapat dicapai melalui kompetensi strategi yang diterapkan oleh pengusaha dalam usahanya. Pada penelitiannya juga menunjukkan adanya hasil yang positif dan signifikan antara kompetensi strategi dengan pertumbuhan usaha di Malaysia.

H1a: Kompetensi strategi dapat mempengaruhi pertumbuhan usaha secara positif.

Kaitan Kompetensi Etika dan Pertumbuhan Usaha. Penelitian yang dilakukan oleh Tamyez et al., (2017) mengungkapkan bahwa kompetensi etika merupakan faktor penting dan memberikan pengaruh positif terhadap pertumbuhan usaha. Menurut Ahmad (2007) dalam melaksanakan sebuah aktivitas bisnis menerapkan sikap transparan dan jujur akan membawa sebuah usaha mencapai tujuan jangka panjang, yaitu pertumbuhan usaha.

Namun, penelitian yang telah dilakukan oleh Tehseen et al., (2019) menyatakan bahwa temuannya memiliki hasil yang negatif dan tidak signifikan antara kompetensi etika dan pertumbuhan UKM. Hasil negatif dan tidak signifikan muncul karena lingkungan 
bisnis di Malaysia sedang tidak stabil dan kompetensi etika diperkirakan lebih mempengaruhi pertumbuhan usaha pada saat kondisi lingkungan bisnis yang lebih stabil. Dengan demikian, dapat disimpulkan bahwa kompetensi etika dengan pertumbuhan usaha dapat memiliki hubungan yang positif ataupun negatif tergantung dengan kondisi lingkungan bisnis pada saat itu.

H2a: Kompetensi etika dapat mempengaruhi pertumbuhan usaha secara positif

Kaitan Kompetensi Strategi dan Kompetensi Jaringan. Menurut penelitian yang telah dilakukan sebelumnya oleh Tehseen et al., (2019) menyatakan bahwa temuannya memiliki hasil yang positif dan signifikan antara kompetensi strategi dan kompetensi jaringan. Tehseen et al., (2019) berpendapat, seorang wirausaha dalam melaksanakan kompetensi strateginya sangat memerlukan peranan dari sumber daya informasi yang dapat mereka peroleh dari adanya jaringan yang terjalin.

H1b: Kompetensi strategi mempengaruhi kompetensi jaringan secara positif

Kaitan Kompetensi Etika dan Kompetensi Jaringan. Hasil penelitian Hasoloan (2018) menyatakan bahwa terdapat hubungan yang positif antara kompetensi etika dengan kompetensi jaringan. Kompetensi etika yang diterapkan dalam bisnis mempengaruhi kepercayaan kepada pihak eksternal bisnis, termasuk pemasok, perusahaan lainnya yang berkaitan, dan juga pelanggan.

H2b: Kompetensi etika mempengaruhi kompetensi jaringan secara positif

Kaitan Kompetensi Strategi terhadap Pertumbuhan Usaha yang Dimediasi oleh Kompetensi Jaringan. Tercapainya kesuksesan dalam bisnis, yaitu pertumbuhan usaha tentu tidak terlepas dari adanya pengembangan strategi untuk menghadapi ketidakpastian lingkungan yang terjadi. Untuk mencapai hal tersebut tentu dibutuhkan adanya hubungan dengan pihak luar dalam membantu memperoleh informasi yang dibutuhkan, maka dari itu penelitian yang telah dilakukan sebelumnya oleh Tehseen et al., (2019) menyatakan bahwa temuannya memiliki hasil yang positif dan signifikan antara kompetensi strategi dan pertumbuhan usaha yang dimediasi oleh kompetensi jaringan.

H1c: Kompetensi strategi mempengaruhi pertumbuhan usaha dengan peran kompetensi jaringan sebagai variabel mediasi secara positif

Kaitan Kompetensi Etika terhadap Pertumbuhan Usaha yang Dimediasi oleh kompetensi Jaringan. Dengan adanya sikap etis, seperti berkata jujur, mau mengakui kesalahan, dan transparan dalam berbisnis akan menimbulkan rasa percaya pelanggan terhadap sebuah usaha yang mengarah pada pertumbuhan usaha (Nguyen et al., 2015).

H2c: Kompetensi etika mempengaruhi pertumbuhan usaha dengan peran kompetensi jaringan sebagai variabel mediasi secara positif

Kaitan Kompetensi Jaringan dan Pertumbuhan Usaha. Penelitian yang serupa juga dilakukan oleh Fernhaber \& McDougall (2016) dan hasilnya menjelaskan bahwa terdapat 
pengaruh yang positif dan signifikan antara kompetensi jaringan terhadap pertumbuhan usaha. Di mana dengan adanya jaringan dapat memberikan informasi yang kredibel dan sangat mempengaruhi pertumbuhan sebuah usaha.

H3: Kompetensi jaringan dapat mempengaruhi pertumbuhan usaha secara positif

Berdasarkan uraian kaitan antar variabel yang ada, maka model penelitian dalam penelitian ini adalah sebagai berikut:

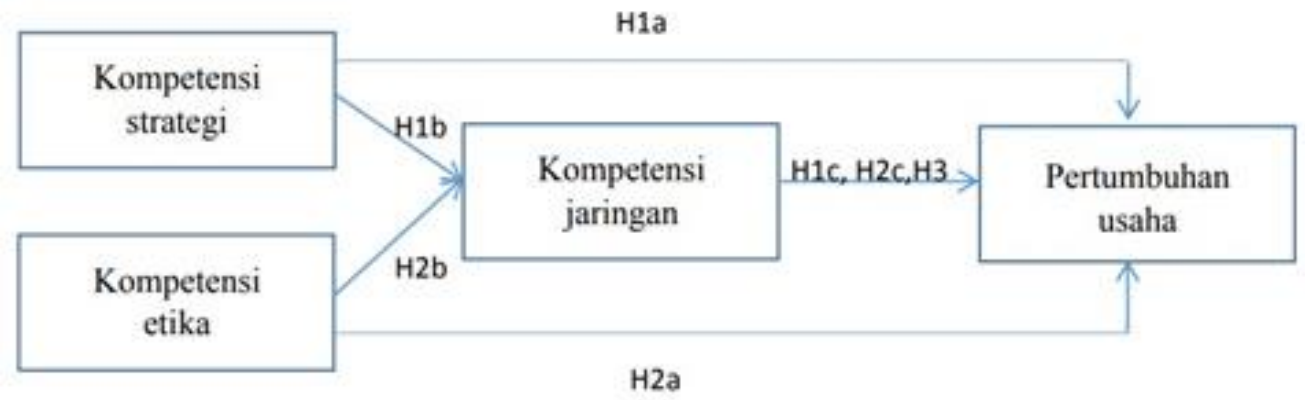

Gambar 2.1

Model Penelitian

\section{METODOLOGI}

Pada penelitian ini desain penelitian yang digunakan adalah deskriptif. Data yang diambil untuk penelitian ini merupakan data primer yang diperoleh dari pengumpulan hasil kuesioner pada usaha UKM grosir dan eceran dalam bidang pakaian di Tanah Abang, Jakarta Pusat. Populasi pada penelitian ini berasal dari sektor UKM grosir dan eceran pakaian di Tanah Abang, Jakarta Pusat.

Pemilihan sampel pada penelitian ini adalah non-probability sampling, di mana anggota dari populasi tidak memiliki probabilitas yang sama untuk terpilih menjadi sampel. Sementara itu, untuk teknik pengambilan sampelnya adalah purposive sampling yang merupakan pengambilan sampel dengan cara menentukan terlebih dahulu kriteria tertentu yang dapat memberikan informasi yang dibutuhkan. Adapun kriteria yang diperlukan agar dapat menjadi responden pada penelitian ini adalah sebagai berikut:

a. Mereka merupakan pengusaha UKM grosir dan eceran di bidang pakaian.

b. Memulai dan aktif terlibat dalam pengelolaan bisnis mereka sendiri atau pemilik dari usaha UKM tersebut.

c. Telah beroperasi minimal 1 tahun.

d. Jumlah karyawan melebihi 5 orang, berdasarkan Badan Pusat Statistik (BPS), jumlah karyawan untuk usaha kecil adalah 5 hingga 19 orang dan unutk usaha menengah adalah 20 hingga 99 orang.

Penelitian ini sebanyak 50 responden yang merupakan pemilik usaha UKM di Tanah Abang, Jakarta Pusat.

Pengukuran variabel-variabel dalam penelitian ini mengacu pada penelitian sebelumnya antara lain sebagai berikut: 


\begin{tabular}{c|c|c} 
Variabel & Pernyataan & Acuan \\
\hline Kompetensi Strategi & 3 pernyataan & $\begin{array}{c}\text { Ahmad (2007) dan Man } \\
\text { \& Lau (2000) }\end{array}$ \\
\hline Kompetensi Etika & 5 pernyataan & Ahmad (2007) \\
\hline Kompetensi Jaringan & 6 pernyataan & Ritter et al, (2002) \\
\hline Pertumbuhan Usaha & 4 pernyataan & $\begin{array}{c}\text { Ahmad (2007) dan } \\
\text { Chandler \& Hanks } \\
(1993)\end{array}$
\end{tabular}

\section{HASIL ANALISIS DATA}

Analisis validitas dilakukan dengan menggunakan convergent validity dan discriminant validity. Convergent validity diukur dengan melihat nilai dari average variance extracted $(\geq 0,5)$ menurut (Henseler et al., 2009) dan loading factors $(>0,7$ atau 0,5 hingga 0,6) menurut (Yamin \& Kurniawan, 2011). Sedangkan discriminant validity dengan melihat nilai dari Fornell-Larcker dan cross loadings. Hasil dari pengujian validitas pada pnelitian ini menunjukkan seluruh variabel dan indikator dalam penelitian ini valid. Menurut Malhotra (2009) pengujian reliabilitas dikatakan reliabel dengan melihat nilai dari composite reliability $(\geq 0,6)$ dan cronbach's alpha $(\geq 0,6)$, pengujian yang telah dilakukan pada penelitian ini menunjukkan bahwa tiap pernyataan yang digunakan untuk mengukur variabel yang ada reliabel.

Pengujian $\mathrm{R}$ square dilakukan untuk mengetahui seberapa besar hubungan antara variabel-variabel independen dapat memprediksi variabel dependen. Nilai $\mathrm{R}$ square yang diperoleh pada penelitian ini sebesar 0,359 untuk kompetensi jaringan, yang artinya sebesar 35,9\% dari variabel kompetensi jaringan dapat dijelaskan oleh variabel-variabel yang ada pada penelitian ini, yaitu kompetensi strategi dan kompetensi etika dan sisanya sebesar 64,1\% dapat dijelaskan oleh variabel lainnya yang tidak diteliti pada penelitian ini. Selanjutnya, nilai $\mathrm{R}$ square dari pertumbuhan usaha sebesar 0,307 , yang artinya sebesar 30,7\% dapat dijelaskan oleh variabel yang diteliti dalam penelitian ini, yaitu kompetensi strategi, kompetensi etika, dan kompetensi jaringan. Sedangkan sisanya sebesar 69,3\% dapat dijelaskan oleh variabel-variabel lainnya. Berdasarkan hasil pengujian nilai $\mathrm{R}$ square dari kompetensi jaringan sebesar 0,359 dan pertumbuhan usaha sebesar 0,307 dianggap substansial.

Selanjutnya, dilakukan pengujian Predictive relevance $\left(\mathrm{Q}^{2}\right)$ digunakan untuk mengetahui apakah variabel yang ada pada penelitian ini dapat memprediksi model yang ada dalam penelitian ini dengan baik atau tidak. Untuk mendapatkan hasil dari $\left(\mathrm{Q}^{2}\right)$ perlu menggunakan metode blindfolding Hair et al., (2017). Nilai $\left(\mathrm{Q}^{2}\right)$ untuk variabel kompetensi jaringan sebesar 0,158 yang artinya hubungan dari kompetensi strategi dan kompetensi etika dapat menjelaskan dengan baik kompetensi jaringan. Sedangkan sebesar 0,111 merupakan nilai dari $\left(Q^{2}\right)$ untuk pertumbuhan usaha, yang artinya hubungan dari kompetensi strategi, kompetensi etika dan kompetensi jaringan dapat menjelaskan dengan baik pertumbuhan usaha dalam model penelitian yang telah dibuat pada penelitian ini. Berdasarkan hasil yang ada dapat disimpulkan bahwa variabel-variabel tersebut mampu memprediksi model dengan baik karena nilai dari $\left(\mathrm{Q}^{2}\right)>0$ (Hair et al., 2011).

Pengujian Uji Goodness of Fit (GoF) dilakukan untuk mengetahui kecocokan suatu model penelitian. Berdasarkan hasil perhitungan GoF yang dilakukan secara manual, dapat 
disimpulkan bahwa penelitian ini memiliki nilai GoF yang besar, yaitu 0,4192 (>0,36) (Tenenhaus, 2005).

Pengujian hipotesis yang dilakukan pada penelitian ini bertujuan untuk mengetahui apakah hipotesis yang terdapat pada penelitian ini diterima atau ditolak, dengan melihat nilai dari path coefficient, $t$-statistics, dan $p$-values yang dihasilkan.

Tabel 1. Hasil Pengujian Hipotesis

\begin{tabular}{|l|c|c|c|}
\hline \multicolumn{1}{|c|}{ Variabel } & $\begin{array}{c}\text { Path } \\
\text { Coefficient }\end{array}$ & t-statistics & p-values \\
\hline $\begin{array}{l}\text { Kompetensi Strategi -> Pertumbuhan } \\
\text { Usaha }\end{array}$ & 0,298 & 2,098 & 0,020 \\
\hline Kompetensi Etika -> Pertumbuhan Usaha & $-0,075$ & 0,444 & 0,329 \\
\hline $\begin{array}{l}\text { Kompetensi Strategi -> Kompetensi } \\
\text { Jaringan }\end{array}$ & 0,274 & 2,546 & 0,007 \\
\hline $\begin{array}{l}\text { Kompetensi Etika -> Kompetensi } \\
\text { Jaringan }\end{array}$ & 0,404 & 4,320 & 0,000 \\
\hline $\begin{array}{l}\text { Kompetensi Strategi -> Kompetensi } \\
\text { Jaringan -> Pertumbuhan Usaha }\end{array}$ & 0,108 & 1,973 & 0,027 \\
\hline $\begin{array}{l}\text { Kompetensi Etika -> Kompetensi } \\
\text { Jaringan -> Pertumbuhan Usaha }\end{array}$ & 0,158 & 2,025 & 0,024 \\
\hline $\begin{array}{l}\text { Kompetensi Jaringan -> Pertumbuhan } \\
\text { Usaha }\end{array}$ & 0,392 & 2,649 & 0,005 \\
\hline
\end{tabular}

Berdasarkan hasil pengujian hipotesis yang telah dilakukan, dapat disimpulkan bahwa dari tujuh hipotesis yang ada, terdapat satu hipotesis yang negatif dan tidak signifikan, yaitu kompetensi etika terhadap pertumbuhan usaha. Sedangkan enam hipotesis sisanya menunjukkan hasil yang positif dan signifikan.

\section{Tabel 2}

Hasil Uji Specific Indirect Effects

\begin{tabular}{|l|c|c|c|}
\hline \multicolumn{1}{|c|}{ Variabel } & $\begin{array}{c}\text { Path } \\
\text { Coefficient }\end{array}$ & t-statistics & p-values \\
\hline $\begin{array}{l}\text { Kompetensi Strategi -> Kompetensi } \\
\text { Jaringan -> Pertumbuhan Usaha }\end{array}$ & 0,108 & 1,973 & 0,027 \\
\hline $\begin{array}{l}\text { Kompetensi Etika -> Kompetensi } \\
\text { Jaringan -> Pertumbuhan Usaha }\end{array}$ & 0,158 & 2,025 & 0,024 \\
\hline
\end{tabular}


Dari hasil yang ada, dapat disimpulkan bahwa kompetensi jaringan mampu memediasi kompetensi strategi terhadap pertumbuhan usaha. Hasil yang serupa juga ditemui pada kompetensi jaringan sebagai variabel mediasi antara kompetensi etika terhadap pertumbuhan usaha.

\section{DISKUSI}

Hasil pengujian H1a menunjukkan bahwa kompetensi strategi dapat mempengaruhi pertumbuhan usaha secara positif dan signifikan. Hasil pada penelitian ini juga sejalan dengan penelitian yang telah dilakukan oleh Tehseen et al.,(2019) yang menyatakan bahwa terdapat pengaruh yang positif dan signifikan antara kompetensi strategi dan kompetensi jaringan. Pada $\mathrm{H} 2 \mathrm{a}$ menunjukkan bahwa kompetensi etika tidak dapat mempengaruhi pertumbuhan usaha secara positif dan signifikan. Hasil yang diperoleh berbeda dengan hipotesis yang telah dibuat dalam penelitian ini. Hasil uji analisis menunjukkan kompetensi etika mempengaruhi pertumbuhan usaha secara negatif dan tidak signifikan. Hasil pada penelitian ini tidak sejalan dengan penelitian yang telah dilakukan oleh Ahmad (2007) yang menyatakan bahwa komptensi etika berpengaruh positif terhadap pertumbuhan usaha. Namun hasil pada penelitian ini sejalan dengan hasil penelitian yang dilakukan oleh Tehseen et al., (2019) yang memberikan hasil bahwa kompetensi etika berpengaruh negatif dan tidak signifikan. Berikutnya, hasil pengujian menunjukkan bahwa H2b menunjukkan variabel kompetensi etika berpengaruh positif dan signifikan terhadap kompetensi jaringan. Hasil pada penelitian ini sejalan dengan penelitian yang telah dilakukan oleh Tehseen et al.,(2019) bahwa kompetensi etika berpengaruh positif dan signifikan terhadap kompetensi jaringan. Pada H1c memberikan hasil bahwa kompetensi strategi dapat mempengaruhi pertumbuhan usaha dengan komptensi jaringan sebagai variabel mediasi secara positif dan signifikan. Penelitian yang dilalukan oleh Tehseen et al.,(2019) juga memberikan hasil yang sama, yaitu terdapat hubungan yang positif dan signifikan antara kompetensi strategi terhadap pertumbuhan usaha yang dimediasi oleh kompetensi jaringan. Dari hasil pengujian yang dilakukan terhadap kompetensi strategi ke pertumbuhan usaha dapat disimpulkan bahwa peran dari variabel mediasi yaitu, kompetensi jaringan adalah partial mediation. Dalam pengujian yang dilakukan pada $\mathrm{H} 2 \mathrm{c}$ memberikan hasil bahwa kompetensi etika memiliki pengaruh positif dan signifikan terhadap pertumbuhan usaha dengan variabel kompetensi jaringan sebagai variabel mediasi. Hal ini sejalan dengan penelitian yang telah dilakukan oleh Tehseen et al., (2019) bahwa terdapat hubungan yang positif dan signifikan antara kompetensi etika terhadap pertumbuhan usaha dengan kompetensi jaringan sebagai variabel mediasi. Dari hasil pengujian yang dilakukan terhadap kompetensi etika ke pertumbuhan usaha, dapat disimpulkan bahwa kompetensi jaringan yang berperan sebagai variabel mediasi adalah full mediation. Pengujian terakhir dilakukan pada $\mathrm{H} 3$, di mana diperoleh hasil kompetensi jaringan dapat mempengaruhi pertumbuhan usaha secara positif dan signifikan. Hasil pada hipotesis ini dapat memperkuat hasil penelitian yang telah dilakukan oleh Fernhaber \& McDougall (2016) bahwa terdapat pengaruh yang positif dan signifikan antara kompetensi jaringan terhadap pertumbuhan usaha.

\section{PENUTUP}


Berdasarkan uji hasil analisis dan pembahasan yang ada, maka disimpulkan bahwa dari tujuh hipotesis yang ada terdapat satu hipotesis yang memberikan pengaruh negatif dan tidak signifikan yaitu, kompetensi etika terhadap pertumbuhan usaha. Selain itu juga terdapat beberapa saran yang sekiranya dapat bermanfaat bagi pelaku usaha UKM bidang pakaian di Tanah Abang, Jakarta Pusat disarankan agar dapat terus melaksanakan kompetensi strategi, kompetensi etika, dan kompetensi jaringan agar dapat mengarah pada pertumbuhan usaha. Untuk penelitian selanjutnya, disarankan dapat menjangkau responden yang lebih banyak daripada yang dilakukan pada penelitian ini, disarankan juga untuk menggunakan variabel independen lainnya selain kompetensi strategi dan kompetensi etika agar dapat memprediksi lebih baik pertumbuhan usaha.

\section{DAFTAR PUSTAKA}

Ahmad, N.H. (2007). A cross-cultural study of entrepreneurial competencies and entrepreneurial success in SMEs in Australia and Malaysia, unpublished PhD thesis, University of Adelaide, Adelaide.

Aquilani, B., Silvestri, C., Ruggieri, A. and Gatti, C. (2017). A systematic literature review on total quality management critical success factors and the identification of new avenues of research, The TQM Journal, Vol. 29 No. 1, pp. 184-213.

Barney, J.B. (1991). Firm resources and sustained competitive advantage, Journal of Management, Vol. 17 No. 1, pp. 99-12.

Bird, B. (1995). Toward a theory of entrepreneurial competency, in Katz, J.A. and Brockhaus, R.H. Sr (Eds), Advances in Entrepreneurship, Firm Emergence, and Growth, JAI Press, Greenwich, CT, pp. 51-72.

Colombo, M.G. and Grilli, L. (2005). Founders' human capital and the growth of new technology-based firms: a competence-based view, Research Policy, Vol. 34 No. 6, pp. 795-816.

Chandler, G.N. and Hanks, S.H. (1993). Measuring the performance of emerging businesses: a validation study, Journal of Business Venturing, Vol. 8 No. 5, pp. 391408.

Hair, J.F., Hult, G.T.M., Ringle, C.M. and Sarstedt, M. (2017), A Primer on Partial Least Squares Structural Equation Modeling (PLS-SEM), Sage, Thousand Oaks, CA.

Hair, J. F., Ringle, C. M., \& Sarstedt, M. (2011). PLS-SEM: indeed a silver bullet. Journal of Marketing Theory and Practice, 19(2), 139-151.

Hasoloan, A. (2018). Peranan Etika Bisnis dalam Perusahaan Bisnis, Warta Dharmawangsa.

Henseler, J., Ringle, C. M., \& Sinkovics, R. R. (2009). The use of partial least squares path modeling in international marketing. Advances in International Marketing, 20, 277320.

Janssen, F. (2009). The conceptualisation of growth: are employment and turnover interchangeable criteria?, The Journal of Entrepreneurship, Vol. 18 No. 1, pp. 21-45.

Lazar, N. and Paul, G. (2015). Entrepreneurial competencies in a business enterprise - an overview, International Journal of Scientific Research, Vol. 4 No. 1, pp. 226-227.

Malhotra, N. K. (2009). Marketing Research: An Applied Orientation. New Jersey: Perason Pretince Hall. 
Man, T.W. and Lau, T. (2000). Entrepreneurial competencies of SME owner/managers in the Hong Kong services sector: a qualitative analysis, Journal of Enterprising Culture, Vol. 8 No. 3, pp. 235-254

Nguyen, B., Chen, C.H.S., Wu, M.S.S. and Melewar, T.C. (2015). Ethical marketing in Singapore, Malaysia, and Thailand, in Nguyen, B. and Rowley, C. (Eds), Ethical and Social Marketing in Asia, Chandos Publishing, Oxford, pp. 55-74.

Pfeffer, J., \& Salancik, G. (1978). The external control of organizations: A resource dependence perspective. New York: Harper and Row.

Rauch, A. and Rijskik, S.A. (2013). The effects of general and specific human capital on long-term growth and failure of newly founded businesses, Entrepreneurship Theory and Practice, Vol. 3 No. 4, pp. 923-941.

Ritter, T., Wilkinson, I.F. and Johnston, W.J. (2002). Network competence: some international evidence, Journal of Business \& Industrial Marketing, Vol. 17 Nos 2/3, pp. 119-138.

Rosli, N.F. and Abdullah, N. (2015). Comparative study on the determinants on SMEs performances in Selangor and Sabah, Malaysia, Handbook on the Emerging Trends in Scientific Research, Vol. 3, pp. 107-111.

Spence, L.J. and Rutherfoord, R. (2001). Social responsibility, profit maximisation and the small firm owner-manager, Journal of Small Business and Enterprise Development, Vol. 8 No. 2, pp. 126-139.

Tamyez, P.F., Ali, J., and Ishak, N. (2017). Entrepreneurial Competencies and Networks in the Construction Industry, International Journal of Applied Engineering Research, Volume 12, Number 23 (2017) pp. 13374-13380

Tehseen, S, Ahmed, F.U., Qureshi, Z.H., Uddin, M,J, and Ramayah, T. (2019). Entrepreneurial competencies and SMEs' growth: the mediating role of network competence, Asia-Pacific Journal of Business Administration, Vol. 11 No. 1, 2019 pp. 2-29.

Tenenhaus, M., Vinzi, V. E., Chatelin, Y. M., \& Lauro, C. (2005). PLS path modeling. Computational statistics \& data analysis, 48(1), 159-205.

Yamin, Sofyan \& Heri Kurniawan. (2009). STRUKTURAL EQUATION MODELING: Belajar Lebih Mudah Teknik Analisa Data Kuesioner dengan Lisrel-PLS. Jakarta: Salemba Infotek. 